\title{
LA PROSA DE ADOLFO BIOY CASARES: EL PODER DE LA SÁTIRA, LA SÁTIRA DEL PODER
}

\author{
Roberta Previtera \\ Université Paris-Sorbonne
}

\begin{abstract}
Resumen: En la ficción de Bioy Casares se puede destacar una fuerte presencia del elemento humorístico. En una primera parte se estudia de qué manera el humor aparece en las obras y, retomando el concepto de ironía, se propone un análisis de los procedimientos textuales utilizados por el autor. En una segunda parte se estudia la relación entre el humor y la evaluación de la situación política contemporánea, observando como a menudo la ironía está acompañada de una voluntad satírica.
\end{abstract}

Palabras clave : Bioy Casares, Humor, Ironía, Sátira, Peronismo

Abstract: In Bioy Casares's fiction a strong presence of humor can be detected. Firstly, we study how humor appears in the texts, focusing on the strategies utilized in the text. In this way we establish a link between humor and irony. Later, we introduce the concept of satire and we analyze the relation between irony and evaluation of contemporary politic context.

Keywords: Bioy Casares, Humor, Irony, Satire, Peronismo

La obra de Adolfo Bioy Casares ha sido objeto de muchos trabajos críticos ${ }^{1}$ que han puesto de relieve su peculiar formulación de lo fantástico. Sin embargo, existen otros aspectos de su obra que, a pesar de haber sido menos estudiados, son recurrentes a lo largo de toda su narrativa. Hablo de esa manera peculiar mediante la cual Bioy introduce la reflexión sobre la contemporaneidad en sus textos: en ellos, el juicio sobre la realidad política y social argentina se realiza a través del humor.

La discusión sobre el humor ha podido contar con importantes contribuciones como la de Schopenhauer, que dedicó al humor un capítulo de El mundo como voluntad y representación; la de Kierkegaard, que escribió su tesis magistral sobre la ironía; la de Bergson, que, en su ensayo Le rire, habló de los mecanismos de la risa; la de Pirandello en 1908 y la de Freud en 1927, solo por citar algunos de los estudios clásicos más conocidos sobre el tema. En todos ellos se evidencia

1 Véase bibliografía. 
la preocupación por definir el humor en relación con otros términos como la ironía y la comicidad. Estos términos, a pesar de ser a menudo usados como sinónimos, designan fenómenos distintos; por eso, antes de empezar mi análisis, creo necesario hacer unas aclaraciones terminológicas.

Según Bergson, el humor nace de la contradicción entre lo real y lo ideal, entre lo que es y lo que debería ser (447). Esta definición nos llama la atención si la comparamos con las definiciones que aparecen en los principales diccionarios del español contemporáneo. En la vigésima edición en línea del diccionario de la Real Academia Española aparece la siguiente definición:

Humor: "modo de presentar, enjuiciar la realidad, resaltando el lado cómico, risueño o ridículo de las cosas".

María Moliner, en la misma línea que la Real Academia, define el humor como:

aptitud para ver o mostrar las cosas por su lado gracioso o ridículo. Con referencia a las personas y a lo que dicen, escriben, dibujan, etc., cualidad consistente en descubrir o mostrar lo que hay de cómico o ridículo en las cosas o en las personas, con o sin malevolencia.

En ambas definiciones desaparece la referencia a la contraposición entre lo real y lo ideal y se asocia el término a lo cómico, a la burla. Lo que pasa es que la palabra "humor", como muchos términos técnicos que han pasado a formar parte del habla cotidiana, ha padecido un deslizamiento semántico y su significado se ha ido acercando al de otros términos. De ahí la frecuente confusión entre humor y comicidad.

El otro binomio complicado desde un punto de vista terminlógico, es HumorIronía. Según el filósofo francés, «L'humour est l'inverse de l'ironie » (448) ya que en la ironía, « on énoncera ce qui devrait être en feignant de croire que c'est précisément ce qui est» (447), mientras en el humor, al contrario, « on décrira minutieusement et méticuleusement ce qui est, en affectant de croire que c'est bien là ce que les choses devraient être » (447).

Es curioso ver que aunque la definición de humor propuesta por Bergson es la que retoman la mayoría de los diccionarios de retórica contemporáneos, en ellos, ironía y humor no son fenómenos en oposición. En el diccionario de poética y retórica de Henry Morier, la definición de "humor" está incluida en la de "ironía". El diccionario de procedimientos literarios Gradus nos dice que el humor es "une acceptation consciente de la différence entre l'idéal et le réel, différence que l’on hésite pas à souligner, ce qui est une façon de se dégager. [...] Il n'est pas incompatible avec l'ironie et emprunte, par exemple, les vois de la pseudo-simulation.» (234-235). La confusión terminológica deriva del hecho 
de que, mientras la ironía es al mismo tiempo tropo y figura de pensamiento², el humor, como afirma Michel Pougeoise en su Dictionnaire de Rhétorique, "n'est pas une figure rhéthorique"(154). El humor pertenece al espíritu, es una postura, que puede manifestarse en un texto, a través del recurso a ciertos procedimientos como es el caso de la ironía.

El humor en Bioy es entonces una actitud, consciente y burlona al mismo tiempo, una postura, un tono que atraviesa sus páginas y que es el resultado de unos procedimientos literarios.

Aunque quizás sea verdad que, como decía el escritor E. B. White, "analizar el humor es como diseccionar una rana. Pocos están interesados y la rana muere en el intento"', me parece que en el caso de Bioy Casares vale la pena que asumamos este riesgo y que nos preguntemos:

- ¿De qué manera esta postura se declara en los textos? Es decir, ¿cuáles son los procedimientos utilizados por Bioy para conseguir un efecto humorístico?

- ¿Esta postura conlleva una evaluación crítica de la realidad? Es decir, va acompañada de una voluntad satírica?

Yo creo que el humor en Bioy es el resultado de un uso consciente de la ironía. Al hablar de ironía, nos encontramos ante un concepto que, como afirma Pere Ballart, "al convertirse en moneda corriente, $[. .$.$] ha pasado de mano en mano en$ las situaciones más dispares y cuanto ha ganado en popularidad lo ha perdido en precisión" (19).

El concepto de ironía ha sido abordado desde muchos puntos de vista. Ante la imposibilidad de dar cuenta de todas sus formulaciones, consideraré aquí solo una particular dimensión del fenómeno: el carácter intertextual de la ironía, es decir, la ironía como forma particular de citación, como veremos a continuación.

El carácter de citación de la ironía ha sido estudiado por primera vez por Sperber y Wilson en 1973 en un artículo titulado "Les ironies comme mentions" y, posteriormente, por Graciela Reyes en su ensayo Polifonía textual: la citación en el relato literario. Reyes, retomando las tesis de Bajtín sobre la novela polifónica, considera la ironía como un caso particular de polifonía textual. La ironía verbal es, según ella, una enunciación polifónica en la que el locutor no se hace cargo de lo que está diciendo, se desdobla y, tras tomar la voz de otro (Reyes habla de "locutor ingenuo"), dice algo sin señalar el carácter de citación de lo que está diciendo. A nivel textual, la enunciación X, pronunciada por el locutor ingenuo, es desmentida por el contexto. Esta incongruencia entre lo que se dice y lo que sería pertinente decir, lleva al interlocutor a buscar otras interpretaciones de

${ }^{2}$ Con respecto a la diferencia entre los distintos tipos de figuras véase el Diccionario de Retórica, crítica y terminología literaria de Angelo Marchese y Joaquín Forradellas.

3 E.B.White, Citas y frases célebres, Netotem Ocio Fun 2.0, www.netotem.com/citas-y-frases-celebres/citas-y-frases-celebres2.asp?aut=E\%20B\%20White\%20(1899-1985)Internet 12-01-2013 
la enunciación X. Un ejemplo sería una situación en la que llueve a cántaros y alguien exclama: “QQué lindo tiempo!”.

En las novelas de Bioy, es el narrador quien se comporta como locutor irónico. Muy a menudo existe una desproporción entre la hipérbole admirativa con la que el narrador presenta a sus personajes y las características reales de los mismos; hay una contradicción entre su presentación elogiosa y la manera en la que ellos actúan o la información que, de ellos, nos proporciona el texto. Un ejemplo puede ser el del doctor Valerga en El sueño de los héroes. El narrador lo presenta como si fuera un guía intelectual para el grupo de los muchachos y nos dice: "El doctor Valerga [era] maestro y modelo de todos ellos" (7). Sin embargo, a lo largo del texto nos enteramos de que el doctor, como muchos inmigrantes de origen italiano, omite sistemáticamente la " $\mathrm{B}$ " cuando pronuncia las palabras en las que aparece el grupo consonántico "BS": "Yo no recuerdo en absolutoafirmó el doctor, sin pronunciar la b” (159).

En otros casos, los personajes están presentados por el narrador como modelos de erudición pero esta presentación resulta desmentida por las lecturas que hacen. Un ejemplo es el mago Taboada. Este es descrito por el narrador como un viejo sabio que intenta convencer al protagonista, Gauna, para que abandone el camino de la violencia y emprenda el de la cultura. Sin embargo, el mago no parece destacarse por sus lecturas. El único libro al que se hace referencia es "un ejemplar encuadernado en cuero repujado de Los simuladores del talento en la lucha por la vida de José Ingenieros4" (111), obra que, a pesar de ser una de las expresiones más reconocidas del Positivismo argentino, no es suficiente para justificar la presentación que se hace del mago.

Un caso parecido al del Mago Taboada es el de Doña Ceferina, la vieja señora que vive en casa de Lucio Bordenave en Dormir al sol. El narrador, para dar prueba de su cultura, la pinta como una incansable lectora: "Lo que no saben es que esta señora [...] leyó todos los libros del quiosco del Parque Saavedra y casi todos los de la escuelita Basilio del Parque Chas, que le queda más cerca" (13). Aunque en el texto no se haga referencia a los títulos o a los autores de los libros que la señora lee, los lugares donde encuentra sus libros -un quiosco y la biblioteca de la escuela Basilio5, centro de enseñanza pseudo religioso de

${ }^{4}$ José Ingenieros (Buenos Aires 1877 - 1925) es considerado uno de los principales representantes del Positivismo en América Latina. Profesor de psicología experimental en la Universidad de Buenos Aires, escribió su tesis doctoral, La simulación en la lucha por la vida, en 1903, de acuerdo con la corriente darwinista que dominaba la Argentina de esos años. Como miembro del partido socialista, defendió la idea de que la lucha de clases era una de las posibles manifestaciones de la lucha por la vida. Cfr.(http://www.biografiasyvidas.com/biografia/i/ingenieros.htm) Internet $12 / 01 / 2013$

${ }^{5}$ En 1917 Blanche Aubreton de Lambert y Eugenio Portal fundan en Buenos Aires la Escuela Científica Basilio. Según los miembros de la escuela los contenidos que se transmiten son mensajes de los espíritus, de la Virgen, de San José y de otros personajes de la historia sagrada y profana. En 1925 la escuela es reconocida "culto espiritista" por el gobierno argentino. En los años 
orientación espiritista- nos dan una idea de sus lecturas. En este caso el número de libros leídos, que ya de por sí no es ninguna garantía de erudición, no ayuda a mejorar la situación, sino que la empeora, contribuyendo a delinear el retrato de una vieja señora ávida de literatura folletinesca.

En el caso de Doña Ceferina, como en el del Doctor Valerga y el del mago Taboada en El sueño de los héroes, se produce un desfase entre lo que nos dice el narrador y lo que hacen los personajes. Tal y como afirma Reyes, podríamos decir que se genera un contraste entre la enunciación del narrador y el contexto de la enunciación. Esto pasa porque los narradores de Bioy, como buenos ironistas, saben cuándo callarse y dejar la palabra al locutor ingenuo. Es así como, cuando creemos que Doña Ceferina es una intelectual, el que nos habla en realidad es el locutor ingenuo de Reyes.

Pero Reyes, en su teoría, da un paso más y nos dice que la enunciación producida por el locutor ingenuo puede ser a su vez una citación encubierta de un discurso anterior, atribuible a un locutor original (LO); esto es, el locutor irónico, a través del locutor ingenuo (el que habla), puede estar citando algo dicho precedentemente por un locutor original (LO). Esta es la parte que me parece más importante en la teoría de Reyes, ya que nos permite construir un puente entre la ironía y la sátira.

Cuando detrás de un enunciado irónico se puede observar la citación de un discurso anterior o de un uso lingüístico ajeno, atribuible a un grupo o acorde a una ideología, la ironía puede conllevar una actitud valorativa hacia el locutor original. En este caso la ironía va acompañada de una finalidad satírica. Eso es lo que, a mi juicio, ocurre en las obras de Bioy Casares.

El Diccionario de Retórica, crítica y terminología literaria de Joaquín Forradellas define la sátira como "un género literario en verso, en prosa o en prosa y verso de carácter polémico, crítico-moralizador o irónico que tiene como objeto la representación de la realidad cotidiana [...]" (360). En su artículo "Ironía, sátira, parodia", Linda Hutcheon habla de la sátira como de una forma literaria que se propone corregir ciertos comportamientos individuales o sociales a través de la caricatura. Su referente es por ende "extratextual". Como afirma Reyes, el discurso ajeno puede aparecer detrás de "un estilo pomposo, una jerga, un cliché, una exageración o un tono de inocencia falsa [...] que evocará a un locutor distinto del locutor real, la otra voz, el otro discurso, el del locutor ingenuo [...] que en su ingenuidad es proclive a repetir lo que dicen por ahí, el discurso oficial, los tópicos.”(167).

que preceden y siguen a la muerte de los fundadores se afirma como movimiento internacional difundiéndose en Uruguay, Paraguay, Brasil, Estados Unidos y en varios países europeos. La escuela se caracteriza por una elaboración sistemática, más pragmática que dogmática, de las doctrinas espiritistas que, a partir de las posiciones de Allan Kardec (1804-1869), incorporan una serie de nociones sobre la rencarnación, la pluralidad de los mundos y los distintos tipos de medianidad. Cfr. (http://www.cesnur.org/religioni_italia/s/spiritismo_03.htm) Internet 12/01/2013 
Yo creo que, en el caso de Bioy, los locutores originales no son personas identificables, el referente de Bioy es más bien un referente colectivo, un discurso dominante, una ideología, un sistema de valores que aparece reflejado en las palabras de los locutores ingenuos.

Lo que se imita no es una enunciación $\mathrm{X}^{1}$, sino los rasgos estilísticos típicos de un habla y los temas recurrentes de un discurso. X es una enunciación "a la manera de", un pastiche. Utilizo el término genettiano aun teniendo consciencia de que los discursos imitados por los personajes de Bioy no son -al menos los que menciono en este artículo- discursos literarios. Sin embargo, me parece que la definición de pastiche satírico dada por Genette (Genette habla de charge) sigue siendo útil ya que insiste en dos rasgos que aparecen en la obra de Bioy: la exageración y la saturación. Esta relación entre el pastiche y la sátira parecería confirmada también por Hutcheon en el artículo citado anteriormente, cuando dice que la sátira puede utilizar la parodia y el pastiche como dispositivos estructurales.

En algunos casos, los discursos de los personajes imitan rasgos típicos del habla popular porteña. Los ejemplos son muchos. Uno de ellos es el caso, ya señalado anteriormente, del doctor Valerga que tiene dificultad para pronunciar el sonido "bs"; otro es el de Lucio Bordenave en Dormir al sol, cuyo discurso está saturado de usos lingüísticos típicos de este habla. A nivel lexical, un uso de la lengua connotado podría ser la presencia obsesiva de la dicción "mi señora" (privilegiada respecto a otras formas posibles como "mujer", "esposa", "cónyuge", "consorte" 6 ) que caracteriza el habla de este último y que es, como nos recuerda Norma Mazzei ${ }^{7}$, un localismo típico de la ciudad de Buenos Aires.

Sin embargo, en la mayoría de los casos, lo que se retoma son sobre todo ideas, convicciones, opiniones comunes de la época. Las afirmaciones contenidas en los discursos de muchos de los personajes de Bioy Casares dan voz a algunas posiciones del gobierno de Perón en materia cultural. Un ejemplo son las reflexiones sobre el problema del teatro en Argentina hechas por el presunto crítico Baumgarten en El sueño de los héroes.

Quisiera exponerle en términos palpables el problema de nuestro teatro. El autor nuevo, joven, argentino, se ahoga, se asfixia, sin contar con la posibilidad de ver corporizada su fantasía [...] ¿Quién va a representarlo? Habría que bajar el cogote de las compañías, aunque más no fuera con la amenaza de la policía montada. Mientras el autor oscuro, imperfecto si se quiere, languidece en la cucha y no logra dar a la luz sus engendros, el ventrudo público, ese dios burgués que inventó el liberalismo francmasón repantigado en las cómodas butacas que alquila a fuerza de oro, pasa revista a las obras que se le antoja,

${ }^{6}$ Cfr. Moliner, María, Diccionario del uso del español, Madrid, Gredos, 2000.

7 Cfr. "Lengua urbana, registro y notas humorísticas de Bioy" en A. De Toro y S. Regazzoni, Homenaje a Adolfo Bioy Casares, op. cit., p.231. 
eligiéndolas, porque no es una marmota, entre lo mejorcito del repertorio internacional. (69-70)

El proyecto de una Argentina libre del yugo de la dependencia económica y cultural de Europa y de los Estados Unidos no fue una invención del Peronismo; nació a fines del siglo XIX y fue central en todos los debates intelectuales de los años '30 del siglo XX. No obstante, el Peronismo se apropió del proyecto y lo transformó en uno de los pilares fundamentales de su discurso ${ }^{8}$.

La operación fue doble: por un lado, Perón puso en marcha un proyecto de "Renovación cultural" y, por el otro, achacó la sujeción a la cultura extranjera a las clases dirigentes que habían dominado la escena política de los últimos años, a aquella oligarquía "que alquila butacas a fuerza de oro", a aquel "liberalismo francmasón” del que habla Baumgarten en su discurso.

Tras estas consideraciones, no es difícil encontrar, en las ideas expuestas por el "presunto" crítico, el eco de las posiciones adoptadas por el régimen.

Sin embargo, no hay que olvidar que, como afirma Rosalba Campra, se trata de "distorsioni ironiche": Baumgarten es considerado en su ambiente un intelectual, sin embargo, su propuesta de amenazar a las compañías teatrales con la policía a caballo nos llama la atención por su ingenuidad e insinúa al lector unas primeras dudas respecto a su capacidad de análisis. El golpe mortal a su estatuto de intelectual está infligido, una vez más, por el lenguaje: frases como "ese dios burgués que inventó el liberalismo francmasón" resultan discordantes con el tono general del discurso, que se caracteriza, en cambio, por la presencia de expresiones coloquiales como "bajar el cogote" (69) o "no es una marmota" (70). Esta disonancia se debe al hecho de que el lector percibe su carácter postizo: se da cuenta de que Baumgarten repite un discurso ajeno, de que las palabras que utiliza no le pertenecen y de que, muy probablemente, repite lo que ha escuchado por ahí. A través del individuo, Bioy se burla de una clase, de las masas que repiten mecánicamente los discursos dominantes, sin darse cuenta de que son un instrumento en manos del poder.

El Peronismo llevó a cabo una política cultural que, a través de la recuperación de las tradiciones autóctonas y del folclore local, se preocupó de exaltar todos aquellos elementos que pudieran considerarse constitutivos de la identidad argentina. El mismo Perón en uno de sus discursos decía:

lo que realmente distingue al argentino del europeo o del africano es su radical correspondencia con una determinada situación geopolítica, su íntimo compromiso moral con el destino de la tierra que lo alberga, y su ineludible referencia a una historia específica que perfila lentamente la

${ }^{8}$ Con respecto a la historia argentina del siglo XX, remito a los estudios de Tulio Halperín Donghi, José Luis Romero, María Seoane, Carlos Floria y César García Belsunce, presentes en la bibliografía. 
identidad del pueblo. [...] La gestación de nuestra cultura nacional resultará de una herencia tanto europea como específicamente americana, pues no hay cultura que se constituya desde la nada, pero deberá tomar centralmente en cuenta los valores que emanan de la historia específica e irreductible de nuestra patria. Muchos de tales valores se han concretado en la cultura popular, que como todo lo que proviene de la libre creación del pueblo, no puede menos de ser verdadera ${ }^{9}$.

El problema fue que, como afirma Marco Aguinis, esta recuperación de la cultura popular se tradujo a menudo en una literatura de escasa calidad, cuyo único objetivo era celebrar el régimen:

En lo cultural se degradó la excelencia. Lo nacional equivalía al folklore. Se confundía arte popular con arte pobre. Es cierto que se recuperaron muchas fuentes y se ampliaron los escenarios. Pero se alió el atraso con la reacción. Se confundió cultura de punta con cultura kitsch; y esto se extendió al cine, la monumentalidad de los actores partidarios, la arquitectura y la escultura oficial. (128)

Bioy no se expresa directamente sobre este tema, sin embargo, las notas irónicas que aparecen en muchos de sus textos, sobre todo en los que escribe en colaboración con Borges, no dejan dudas con respecto a su posición. En el cuento "La salvación por las obras", aparece un personaje llamado el Baulito. Este parece una caricatura de Perón. De él se dice: “[es] por derecho propio un elemento popular y querido en todos los círculos, particularmente donde haya coristas y caballos" (509). Los caballos son probablemente una referencia al pato, deporte a caballo declarado en 1953, por voluntad de Perón, deporte nacional argentino; hablar de coristas, en cambio, es probablemente una manera de burlarse de Eva Perón, que empezó su carrera como subrette. Tras haber sido nombrado subsecretario de cultura, en una conversación con su mano derecha, el Baulito reconoce lo siguiente: "yo no pesco mucho de cultura, pero por suerte cuento con un ladero que ha escarbado en estas macanas de pe a pa" (515). La referencia al programa cultural de Perón se hace explícita unas páginas más adelante, cuando se dice que el Baulito está a punto de firmar "el anteproyecto para la primera edición de Jornadas Folclóricas Provinciales, a celebrarse en ciudades capitales de nuestro interior" (516). Otro instrumento utilizado por Perón para ampliar su apoyo fue la participación directa de las masas en la política a través de procesiones y manifestaciones. Como afirman Carlos Floria y César García Belsunce:

9 J.D.Perón, “Modelo Argentino para el Proyecto Nacional”, El Historiador, (http://www.elhistoriador.com.ar/documentos/vuelta_de_peron/modelo_argentino_2p.php) Internet 11-01-2013 
esta relación líder-masas constituyó una de las notas distintivas del populismo peronista. La movilización de las masas, espontánea las más de las veces al principio, dirigida desde el poder otras, constituyó uno de los elementos característicos de la comunicación entre Perón y su pueblo. Estas reuniones revestían el carácter de fiestas populares acompañadas o seguidas de asuetos o feriados como el famoso "San Perón" (144).

Más allá de las referencias puntuales a episodios reales, lo que llama la atención en los textos de Bioy es la capacidad de dar voz, a través de los discursos de sus personajes, a las ideas dominantes de su tiempo. La tendencia de la cultura peronista a buscar en todo la presencia del elemento folclórico es ridiculizada en muchos cuentos. En "Las formas de la gloria", esta tendencia es la causa de la incomprensión que suscitan las obras del escritor Clodomiro Ruiz. Este, entrevistado por Tullio Savastano, confiesa: "Yo había usado la palabra "recado" en el sentido de mensaje o misiva, que tuvo su auge años atrás, pero los profesores y los críticos, todos a una, lo interpretaron como la típica montura de nuestro gaucho" (516). La gauchesca fue una de las tradiciones literarias más valoradas por el régimen. El folclore y el contenido de reivindicación social que la caracterizan hicieron de ella un modelo ideal de literatura nacional en contraposición a los modelos europeos. La sátira de este pasaje es doble: por un lado, Borges y Bioy expresan su desaprobación frente a una idea de literatura que, degradada a mero instrumento de propaganda, se ha convertido en estéril proposición de un modelo; por el otro, a través del inciso "que tuvo su auge años atrás", se refieren probablemente a los mensajes a la nación mandados por Perón durante su exilio.

El otro tema recurrente en los discursos de los personajes de Bioy es el chovinismo. Objeto de burla, no es el orgullo patriótico sino su exasperación, esa presunción que lleva a un personaje como Vidal, el protagonista de La guerra del cerdo, a decir: "A caballo ando bien, como cualquier argentino" (44). Una actitud parecida caracteriza al protagonista del cuento "De un mundo a otro", Javier Almagro, que está convencido de que algunos alimentos y algunas bebidas solo existen en Argentina. Su chovinismo aparece desde el principio de su aventura cuando, al caer en un planeta desconocido, está seguro de encontrarse en el barrio de Palermo, en Buenos Aires. Cuando se da cuenta, no sin experimentar cierta irritación, de que el Monumento a los españoles no está en su lugar, decide ir a un café y pedir un "sandwich con miga", seguro de que este tipo de sandwich solo existe en Argentina. Por eso, cuando el mozo le dice que los "sandwiches con miga" existen también en su país y que la bebida típica del lugar es una infusión verde a base de yerba, el protagonista se siente defraudado.

Aunque muy a menudo las víctimas de la ironía sean las clases populares, desde mi punto de vista, el objetivo real de la sátira es otro. Ellas repiten unos discursos que están formulados por otros. Los años cuarenta y cincuenta 
fueron años de grandes cambios para Argentina. La creciente industrialización, la inmigración y la urbanización estaban cambiando rápidamente el aspecto del país. Además la llegada del Peronismo, para bien o para mal, estuvo acompañada de una serie de transformaciones en la manera de ver la política que determinaron la aparición de un nuevo actor social en la escena política: las masas. José Luis Romero en su Breve Historia de la Argentina afirma que, "tras catorce años de gobierno radical, [...] había quedado descubierto un hecho decisivo: el país criollo se desvanecía poco a poco y por sobre él se constituía una nueva Argentina, cuya fisionomía esbozaba la cambiante composición de la sociedad” (174). Con la llegada del Peronismo, “[...] la relación entre oligarquía y masas populares quedaba planteada en el país en nuevos términos, porque los sectores obreros urbanos habían crecido considerablemente y habían adquirido no solo experiencia política, sino también el sentimiento de su fuerza como grupo social." (205)

E1 verdadero objeto de la sátira de Bioy no son, o al menos no solamente, las clases populares sino la operación con que Perón estaba llevando las masas al centro de la vida política del país. Este juicio negativo aparece en toda la obra de Bioy. En Guirnalda con amores encontramos un breve texto titulado emblemáticamente "Altivez":

Altivez.

Horacio, el hombre del garaje, que antes de la revolución llegaría a ser una personalidad, declaró: - Yo nunca me ocupé de política. De fobal, de carreras de autos y de motos, todo lo que quiera; pero le juro que en política estoy, lo que se dice, limpio: nunca me ha importado ni esto. No le niego que si un día tengo la obligación moral y para asegurar el bullón hay que inscribirse, me inscribo. Pero mientras no haya necesidad, no bajo el cogote. Yo soy así. Al mismo Horacio debemos la observación: hace un fresquito que da qué pensar. (92)

La revolución de la que se habla es probablemente una referencia a las manifestaciones de 1946, llevadas a cabo por las masas populares para devolver el poder a Perón. A través de la figura de Horacio, Bioy realiza un retrato caricatural del peronista modelo. Su lenguaje coloquial ("asegurar el bullón" y "bajar el cogote"), sus errores de pronunciación ("fobal") y los temas de sus conversaciones (fútbol y carreras) nos dan una idea de su origen social. La frase "si para asegurar el bullón hay que inscribirse, me inscribo" quiere recordar probablemente una medida de 1952 que impedía el acceso a la función pública a todos los que no estuvieran inscritos en el partido peronista. Para Horacio, su desinterés hacia la política es motivo de orgullo: "en política estoy, lo que se dice, limpio". ¿Cómo no leer en esta afirmación el eco de la retórica populista con que Perón, denunciando la corrupción de la clase política que lo había 
precedido, se jactaba de no tener antecedentes políticos? Según Eliseo Verón y Silvia Sigal, su entrada en la escena política sigue "el modelo de la llegada": Perón legitimó su posición de recién llegado presentándose como el "hombre nuevo" que llega desde afuera. Por supuesto, en el caso de su primera aparición en los años cuarenta, no se trataba de un afuera geográfico sino metafórico: él no formaba parte del ambiente político argentino, venía del cuartel y, por lo tanto, estaba alejado de la corrupción y de la degeneración moral característica de la vida política argentina. Estas hipótesis estarían confirmadas por los discursos. El 12 de agosto de 1944, Perón se define a sí mismo como "un humilde soldado que cumple con un deber impuesto por la hora" (31) Como subraya Verón, "ese pasaje del cuartel al Estado, es evidentemente una entrada en la política, pero la transición no será nunca explicitada en estos términos, la política es lo que ha permitido que la Patria se deteriore, la política es conflicto"(37). En un discurso del 10 de agosto de 1944, aparece claramente cómo el concepto de partido político es remplazado por Perón por un concepto más amplio: la patria: "No soy nada más que argentino; no tengo otra ideología que el pueblo de mi patria, ni otro partido cheque mi patria" (31). Una operación análoga es llevada a cabo con el concepto de ideología, que termina coincidiendo con la aspiración al bien común. Desde el principio el movimiento peronista construyó su discurso alrededor del concepto de unidad nacional. Ya en un discurso de 1943, Perón decía: "la unidad nacional debe ser como la estrella polar para el pueblo argentino". En el discurso del $1^{\circ}$ mayo de 1950, Perón aclaraba su concepto de unidad nacional, afirmando que esta no debía confundirse con la pertenencia de todos los argentinos a la misma bandera política: "La unidad nacional no significa la unión de todos los habitantes de la Nación a la sombra de una sola bandera política. [...] es la coincidencia fundamental de todos en orden a los principios esenciales que deben orientar la marcha de la nación" (67). Sin embargo, esta libertad política era solo nominal.

De hecho, como el único modo para contribuir al bienestar del país era hacerse peronista, quien no apoyaba este proyecto, iba automáticamente en contra de la patria y, por lo tanto, no era digno de considerarse argentino. El discurso del $1^{\circ}$ de mayo de 1950 sigue así:

Esos mismos principios esenciales resplandecen ahora, como estrella polar de la Nación, en el Preámbulo de su nueva Constitución Justicialista y ningún argentino bien nacido puede dejar de querer, sin renegar de su nombre de argentino, lo que nosotros queremos cuando afirmamos nuestra irrevocable decisión de constituir una nación socialmente justa económicamente libre

${ }^{10}$ De ahora en adelante todos los discursos de Perón serán citados según las versiones que aparecen en el libro Perón o muerte de S.Sigal y E. Verón. 
y políticamente soberana. [...] Ningún argentino de bien puede negar su coincidencia con los principios básicos de nuestra doctrina sin renegar primero de la dignidad de ser argentino (67).

El retrato que Bioy hace de Horacio es un ejemplo de su relación con las masas. El juicio de las masas que aparece en los textos puede llegar a ser muy negativo. Las masas están privadas de toda capacidad crítica y se dejan fascinar por la demagogia del líder del momento. Esta posición está expresada claramente por Vidal en Diario de la guerra del cerdo:

Deploraba es verdad los argumentos del caudillo, más enconados que razonables; condenaba sus calumnias y sus embustes, pero no ocultaba la admiración por sus dotes de orador, por la cálida tonalidad de esa voz tan nuestra y, declarándose objetivo, reconocía en él y en todos los demagogos el mérito de conferir conciencia de la propia dignidad a millones de paria. (8)

El caudillo del que se habla hace pensar mucho en Perón. Las "dotes de orador" son seguramente el primer elemento que nos lo recuerda, sin embargo, es a través de la frase "por la cálida tonalidad de esa voz tan nuestra" que la referencia se hace más explícita. Aquí Bioy está atacando uno de los pilares fundamentales de la retórica peronista: la "argentinidad" del presidente, es decir, el discurso que legitima todas sus acciones como expresión de la voluntad del pueblo argentino. Todo el pasaje contiene una fortísima carga polémica, no obstante, la sátira alcanza su ápice cuando se habla de "los argumentos [del caudillo] más enconados que razonables”. ¿Cómo no pensar en las modalidades con las que el Peronismo reclamaba la adhesión del pueblo al gobierno? En uno de sus discursos Eva Perón decía: "nadie se hará justicialista si primero no es peronista de corazón, y para ser peronista, lo primero es querer a Perón con toda el alma. [...] Aquí no necesitamos muchas inteligencias sino muchos corazones" (Perón o muerte, 204).

Todos estos discursos ajenos que aparecen en las palabras de los personajes o que están subrayados por los comentarios del narrador se vuelven protagonistas absolutos en las obras de carácter no narrativo; me refiero a las tres ediciones del Diccionario del argentino exquisito. Ahí el juego intertextual alcanza su cumbre, y la palabra ajena está exhibida a través de las definiciones que se atribuyen a los términos ${ }^{11}$. Me gustaría concluir citando algunas de las definiciones cuya carga satírica me parece particularmente evidente: ulterior.

11 El análisis de la sátira en las obras de carácter no narrativo podría motivar una reflexión 
Carisma: don que se encuentra en los sujetos más insospechables (carismáticos).

"A esos fulanos de tanto carisma

Tarde o temprano les rompen la crisma"

(D. Perazo, Nadie la talla, Buenos Aires, 1974)

Salida constitucional: Panacea o, mejor dicho, "el florido sendero que conduce al fuego inextinguible”, según William Shakespeare, citato por el señor Suárez. Aglutinante: (Peronismo fino). "Comunicó ideales aglutinantes a la mesa partidaria”.

Realizarse: "Un general que no llega a la presidencia, no se realiza".

\section{BIBLIOGRAFÍA}

\section{Obras}

Bioy Casares, A., El sueño de los héroes, Buenos Aires, Losada, 1954.

, Guirnalda con amores, Buenos Aires, Emecé, 1959.

, La invención de Morel, Buenos Aires, Alianza Emecé, 1972.

, Diario de la guerra del cerdo, Madrid, Alianza Tres, 1973.

, Historias fantásticas, Buenos Aires, Alianza Emecé, 1976.

, (con el seudónimo de Javier Miranda), Breve diccionario del argentino exquisito,

Buenos Aires, Barros Merino, 1971.

, Breve diccionario del argentino exquisito, Buenos Aires, Emecé, 1978.

, El héroe de las mujeres, Madrid, Alfaguara, 1978.

, Dormir al sol, Madrid, Alianza, 1979.

, Historias de amor, Madrid, Alianza Emecé, 1981.

, Aventura de un fotógrafo en La Plata, Buenos Aires, Emecé, 1985.

, Historias desaforadas, Buenos Aires, Emecé, 1986.

, Una muñeca rusa, Buenos Aires, Tusquets, 1991.

, Historia prodigiosa, Madrid, Ediciones de la Universidad de Alcalá de Henares, 1991.

, De un mundo a otro, Buenos Aires, Temas, 1998.

, Descanso de caminantes: diarios intimos, Buenos Aires, Editorial Sudamericana, 2001.

Borges, J.L. y Bioy Casares, A., Crónicas de Bustos Domecq, Buenos Aires, Losada, 1967

, Seis problemas para don Isidoro Parodi, Madrid, Alianza, 1998.

, Nuovi racconti di Bustos Domecq, Milano, Franco Maria Ricci Editore, 1985.

Borges, J.L. y Bioy Casares, A.,y Ocampo, S., Antología de la literatura fantástica, Buenos Aires, Editorial Sudamericana, 1971.

\section{Estudios críticos}

Aguinis, M., El atroz encanto de ser argentinos, Buenos Aires, Planeta, 2001.

Bachtin, M., Estetica e romanzo, Turín, Einaudi, 1979. 
Ballart, P., Eironeia. La figuración irónica en el discurso literario moderno, Barcelona, Quaderns Crema, 1994.

Barrenechea, A. M. y Speratti Piñero, E. S., La literatura fantástica en Argentina, México, Imprenta Universitaria, 1957.

Barrera López, T., De fantasías y galanteos, Roma, Bulzoni, 2001.

Bastos, M. L., "Desapego crítico y compromiso narrativo: el subtexto de El sueño de los héroes", Texto y Contexto en la literatura iberoamericana, Madrid, Benzal, 1980, pp. $21-31$.

Bergson, H., "Le rire", Euvres complètes, París, Presses Universitaires de France, 2001, pp. 383-485.

Binello, D., Il diritto non cade in prescrizione, Roma, Ediesse, 2002.

Campra, R., "El sueño de los héroes de Bioy Casares: la clase como destino" ["El sueño de los héroes di Bioy Casares: la classe come destino", 1981]. Adolfo Bioy Casares. Valoración múltiple, Ed. José Miguel Sardiñas, La Habana, Casa de las Américas, 2008.

, Como con bronca y junando... La retórica del tango, Buenos Aires, Hachette, 1996. , Reformulación de lenguajes y formulación ideológica. Una lectura de la ironía en Adolfo Bioy Casares, Roma, Bulzoni, 1990.

."Lo fantástico: una isotopía de la transgresión" ("Il fantastico: una isotopia della trasgressione, 1981). Teorias hispanoamericanas de la literatura fantástica, Ed. José Miguel Sardiñas, La Habana, Casa de las Américas, 2007.

, Territorios de la ficción. Lo fantástico (Territori della finzione. Il fantastico in letteratura, 2000). Sevilla, Renacimiento, 2008.

Camurati, M., Bioy Casares y el alegre trabajo de la inteligencia, Buenos Aires, Corregidor, 1990.

Cicero, M. T., Dell'oratore, Zanichelli, Bolonia, 1975, 3 vol., libro II

De Costa, R., El humor en Borges, Madrid, Cátedra, 1999.

De Toro y S. Regazzoni, A., Homenaje a Adolfo Bioy Casares, Frankfurt-Madrid, Vervuet- Iberoamericana, 2002.

Dupriez, B., Gradus. Les procédés littéraires. Dictionnaire, Union générale d'Éditions, 1984.

Floria, C. y García Belsunce, C., Historia política de la Argentina contemporánea, Madrid, Alianza, 1988.

Freud, S., Les mots de Freud (textos recogidos por Alain de Mijolla), París, Hachette, 1982.

Galeota Cajati, A., Fantastico e letterarietà nei racconti di Adolfo Bioy Casares, Nápoles, Annali della facoltà di Lettere e Filosofia dell'Università di Napoli, No 22 (19791980), pp. 326-362.

Garavelli Mortara, B., Manuale di retorica, Milán, Bompiani, 1997.

Genette, G., Palimpsestes: la littérature au second deegré, París, Éditions du Seuil, 1982. 
Gossy, H., «L'idéologie raciale à l’ère péroniste et ses conséquences sur l'immigration juive en Argentine", Cabiers du Centre de Recherche Ibéro-américaine de Rouen (CRIAR), Université de Rouen, No 2, pp. 65-89.

Halperín Donghi, T., Historia contemporánea de América Latina, Madrid, Alianza, 1990.

Hutcheon, L., «Ironie, satire, parodie. Une approche pragmatique de l'ironie», Poétique, No 46 (1981), pp. 140-155.

, «Ironie et parodie: stratégie et structure», Poétique, No 36 (1978), pp. 467-477. , A theory of parody. The teachings of twentieth century art forms, Nueva York, Methuen, 1985.

Kerbrat-Orecchioni, C., «L'ironie comme trope», Poétique, No 41 (1980), pp. 108-127.

Marchese, A. y Forradellas, J., Diccionario de retórica, crítica y terminología literaria, Barcelona, Ariel, 1994.

Mizzau, M., L'ironia. La contraddizione consentita, Milán, Feltrinelli, 1984.

Morier, H., Dictionnaire de poétique et de rhétorique, Presses universitaires de France, 5 éd., 1998.

Muecke, D. C., «Analyses de l'ironie», Poétique, No 36 (1978), pp. 478-494.

, The compass of irony, Londres, Methuen, 1969.

Murat, N., "Conversación de Borges con Napoleón Murat 1963”, “Apéndice documental" de la edición de Dos Fantasías memorables de J. L. Borges y A. Bioy Casares, Buenos Aires, EDICOM, 1971, 59-62.

Pirandello, L., L'Humour et autres essais, París, M. de Maule, 1988.

Pougeoise, M., Dictionnaire de rhétorique, París, A. Colin, 2001.

Quintilianus, M. F., Institutio Oratoria, Einaudi, Turín, 2001.

Reyes, G., Polifonía textual. La citación en el relato literario, Madrid, Gredos, 1984.

Romera Rozas, R., L'univers humoristique de Jorge Luis Borges et Adolfo Bioy Casares. París, L'Harmattan, 1995.

Romero, J. L., Breve Historia de la Argentina, Buenos Aires, Editorial Anesa Huemul, 1979.

SAntulli, F., Le parole del potere, il potere delle parole. Retorica e discorso politico, Milán, Franco Angeli, 2005.

Seone, M., Argentina paese dei paradossi, Bari, Laterza, 2004.

Schopenhauer, A., Il mondo come volontà e rappresentazione (trad. di Ada, Vigliani), Milán, Mondatori, 1989 (Die Welt als Wille und Vorstellung, 1819).

Todonov, T., La letteratura fantastica (trad. di Klersy Imberciadori), Milán, Garzanti, 1977 (Introduction à la littérature fantastique, 1970).

Ulla, N., Aventuras de la imaginación. De la vida y los libros de Adolfo Bioy Casares, Buenos Aires, Corregidor, 1990.

Verón, E. y Sigal, S., Perón o muerte: los fundamentos discursivos del fenómeno peronista, Buenos Aires, Eudeba, 2004. 
Nombre del autor: Roberta Previtera

Dirección-e: $\quad$ robiprevi@hotmail.it

Dirección postal: $\quad 75$, rue Claude Bernard, Paris 75005

Fecha de recepción: 22/01/2013

Fechade aceptación: 22/09/2013 